\title{
Administration of Very Low Doses of Estradiol Modulates the LH Response to a GnRH Bolus and the LH and Cortisol Responses to Naloxone Infusion in Patients with Functional Hypothalamic Amenorrhea (FHA): A Pilot Study
}

\author{
Alessandro D. Genazzani ${ }^{1, *}$, Giulia Despini ${ }^{1}$, Alessia Prati ${ }^{1}$, Alba Manzo ${ }^{1}$, Tabatha Petrillo ${ }^{1}$, \\ Veronica Tomatis ${ }^{1}$, Andrea Giannini ${ }^{2}{ }^{2}$ and Tommaso Simoncini ${ }^{2}$ \\ 1 Gynecological Endocrinology Center, Department of Obstetrics and Gynecology, University of Modena and \\ Reggio Emilia, 41121 Modena, Italy; giulia.despini@hotmail.it (G.D.); alessia.prati@yahoo.it (A.P.); \\ albamanzo1@gmail.com (A.M.); tabathap@libero.it (T.P.); veronica.tomatis91@gmail.com (V.T.) \\ 2 Department of Obstetrics and Gynecology, University of Pisa, 56126 Pisa, Italy; \\ andrea.giannini@unipi.it (A.G.); tommaso.simoncini@med.unipi.it (T.S.) \\ * Correspondence: algen@unimo.it
}

Received: 23 May 2020; Accepted: 4 June 2020; Published: 8 June 2020

\begin{abstract}
Background: Functional Hypothalamic Amenorrhea (FHA) is a stress-induced blockade of the reproductive axis. Such impairment is mainly due to altered control of GnRH-induced gonadotropin secretion as well as alterations of other endocrine functions. Methods: Seventeen patients with FHA participated in the study. Basal hormonal profiles and GnRH and Naloxone tests for LH (Luteinizing Hormone) and for LH and cortisol responses, respectively, were performed before and after two weeks of administration of a very low dose of estradiol (2.5 ng two times a day). Results: The treatment improved both gonadotropins, mainly LH. The LH response to the GnRH test improved in terms of the peak amplitude, as evaluated using Instantaneous Secretory Rates (ISR) computation. Moreover, when performing the Naloxone test after the treatment interval, FHA patients showed a quicker LH response and recovery of the cortisol response. Conclusions: Our study supports the relevance of very low dose estradiol priming to promote and restore impaired neuroendocrine function in patients with FHA.
\end{abstract}

Keywords: functional hypothalamic amenorrhea; FHA; hypoestrogenism; stress; naloxone; GnRH test; positive feedback

\section{Introduction}

Secondary amenorrhea is a common condition that is characterized by the lack of a menstrual cycle for at least 3 months and can be related to several clinical situations [1-5]. Typically, Functional Hypothalamic Amenorrhea (FHA) is a kind of amenorrhea that occurs with no concomitant systemic or hormonal diseases [1-4,6-9], and it covers up to $35 \%$ of cases of secondary amenorrhea [6-8]. FHA is quite a complex clinical situation, since it is characterized by a constellation of neuroendocrine impairments $[1-4,6-8]$ that all lead to the failure of reproductive ability due to the presence of reduced or very low LH plasma levels, and almost no changes of FSH, with abnormal pulsatile release [10,11].

The occurrence of FHA has been mainly associated with stress and/or stressful conditions. The stressors that mostly act on the reproductive blockade are dieting, psychological stress, or excessive physical exercise, or combination of them, which can disrupt the control of ovarian function by hypothalamic-pituitary activity $[1,2]$. Hypothalamic and extra-hypothalamic areas are negatively 
affected by all these kinds of stressors, and specific defensive responses are induced by the many centers that are strategically located in these areas and inside the hypothalamus, such as those for the control of food intake, body temperature, sexual function, sleep regulation, and reproduction $[8,12]$.

The occurrence of amenorrhea in general, and in particular in patients with FHA, induces a hypoestrogenic condition that negatively affects most of the estrogen-sensitive organs if it is not resolved within a reasonable span of time [13-15]. In fact, the occurrence of osteopenia, as well as mood and/or behavior diseases and vaginal atrophy are common clinical signs reported by these patients [14]. Removal of stressors and/or hormonal treatment are the logic therapeutic strategies that can be applied $[13,14]$. Indeed, in these patients, the use of estro-progestin preparations, especially those containing estradiol, might be helpful for restoring an estrogenic milieu that could counteract the negative effects of long-term hypoestrogenic states.

Recently, we reported the positive effects of short- (10 days) [16] and long-term (8 weeks) estriol administration in a group of FHA patients [17]. We observed an increase in LH plasma levels $[16,17]$ and the restoration of a normal response to the gonadotropin-releasing hormone $(\mathrm{GnRH})$ stimulating test $[16,17]$. These findings suggest that the administration of a weak estrogen, like estriol, modulates the neuroendocrine control of the hypothalamus-pituitary unit since it permits a spontaneous increase in GnRH-induced LH synthesis and release in hypogonadotropic patients with FHA. In addition, estriol was found to be effective for improving the amplitude of the gonadotropin response to an exogenous GnRH bolus, thus demonstrating a specific synergic effect at the pituitary level $[16,17]$.

On this basis, we aimed to evaluate whether such effects might occur after administering a very low estradiol dose, as low as 5 ng every day for 12 weeks and evaluating the response to GnRH and a naloxone bolus of LH and cortisol. To better determine the pituitary response to the GnRH stimulation, a deconvolution algorithm was used to analyze LH plasma concentrations.

\section{Materials and Methods}

\subsection{Patients}

Among the patients attending the outpatient ambulatory at the Gynecological Endocrinology Centers at the University of Modena and Reggio Emilia, Italy for functional hypothalamic amenorrhea (FHA), seventeen patients $(n=17)$, with a mean age of $24.5 \pm 1.7$ years (mean \pm standard error of the mean [SEM]) were selected for participation in the study. All of them had specifically requested not to be treated with estro-progestin preparations.

After giving their informed consent, the patients were included on the basis of the following criteria: (1) amenorrhea in the last 6 months; (2) no presence of metabolic diseases; (3) plasma levels of LH below $3 \mathrm{mIU} / \mathrm{mL}$, as the mean of the concentrations of three consecutive samples over a span of time of $30 \mathrm{~min}$; (4) body weight within the normal range for their age and height (i.e., a body mass index (BMI) not below $19 \mathrm{~kg} / \mathrm{m}^{2}$ ) in the last 6 months; (5) presence of stressful events before the onset of amenorrhea, such as problems with family, school, or work, or psychosocial stress (psychiatric diseases were excluded using the DSM IV criteria [18]); (6) no training for agonistic purposes; and (7) no adrenal, thyroid, or prolactin (PRL) diseases.

All patients were asked to make no changes to their lifestyles and to undergo the standard clinical procedure of our center to address the clinical and hormonal aspects of their amenorrhoeic condition. This procedure includes a baseline hormonal examination (LH, FSH, prolactin (PRL), estradiol (E2), cortisol, androstenedione (A), testosterone (T), progesterone (P), insulin (I)), a GnRH test (10 mg in bolus) for LH and FSH (Follicle Stimulating Hormone) determination, and a Naloxone test (4 $\mathrm{mg}$ in bolus) for LH and cortisol determination.

Patients underwent these hormonal checks before and after administration of $2.5 \mathrm{ng}$ of alcoholic solution of estradiol (GUNA Beta Estradiol D6) eluted in $2 \mathrm{~mL}$ of water two times per day (at 10 a.m. and at 10 p.m.), without having anything to drink and/or eat, for 3 months (90 days). The patients 
were instructed to maintain this small amount of water under the tongue for 20-30 s at least, and then they were permitted to swallow it.

The GnRH test, for evaluation of the LH response, was performed by inserting a heparin well in an antecubital and sampling before injecting the GnRH bolus (10 $\mu \mathrm{g}$ of Leuprolide acetate at time 0 ) and sampling every $10 \mathrm{~min}$ for $140 \mathrm{~min}$ to give a total of 15 samples.

The Naloxone test, for the evaluation of the responses of both LH and cortisol, was performed on the following day by inserting a heparin well in an antecubital vein $20 \mathrm{~min}$ before injecting the Naloxone bolus (Naloxone chlorhydrate, Narcan) at time 0 and sampling blood at -15 and $+15,+30$, $+45,+60,+90$, and +120 min.

The study protocol was approved as an observational study by the Human Investigation Committee of the University of Modena and Reggio Emilia, Italy (Registration No. 181/12).

\subsection{Assay}

All samples from each patient were assayed in the same assay. The determination of LH and FSH concentrations was done using an immunofluorimetric assay (IFMA), which has been described elsewhere $[10,11]$, with a minimal detectable dose of $0.1 \mathrm{mIU} / \mathrm{mL}$. The cross-reactivity of free $\alpha$ and $\beta$ subunits of LH, FSH, and TSH was less than $2 \%$ [11]. The intra-assay and inter-assay coefficients of variation were $4.8 \%$ and $7.2 \%$, respectively.

Plasma PRL, P, A and cortisol were determined by radioimmunoassay (Radim, Pomezia, Italy), as previously described [19]. Based on two quality-controlled samples, the average within- and between assay coefficients of variation were $4.0 \%$ and $9.4 \%$.

The serum concentration of E2 was measured by electrochemiluminescence immunoassay using the Elecsys E2 II reagent kit from Roche Diagnostics GmbH, Mannheim, Germany, with the sensitivity being $4.5 \mathrm{pg} / \mathrm{mL}$. Plasma insulin was determined using an immunoradiometric assay (BioSource Europa S.A., Nivelles, Belgium). Based on two quality-controlled samples, the average within- and between-assay coefficients of variation were $4.3 \%$ and $11.4 \%$, respectively.

\subsection{Instantaneous Secretory Rates (ISR) Computation for the GnRH Stimulation Test}

The program Detect for pulse analysis [20-22] was used to compute the instantaneous secretory rates (ISR) to evaluate the LH secretory rate $[20,23]$ of the LH-induced response to the GnRH bolus. Plasma hormone levels can be considered to be the difference between the input from the pituitary and output from all the organs and tissues responsible for the metabolic clearance of that hormone. Since both the clearance rate constants and the half-life for LH are known, the ISR were computed with a specific algorithm that is included in the Detect program [20]. The duration of the pulses found on ISR is the duration of the secretory bursts from the gonadotropes. The rate constants for LH clearance were set as previously estimated elsewhere [24]. The first and second component rate constants were set at half-lives of 17.8 and $90.0 \mathrm{~min}$, with fractional amplitudes of 0.62 and 0.38 , respectively. The variance model used for the ISR was computed as $\mathrm{s}^{2}$ isr $=2 \times \mathrm{s}^{2} \mathrm{x}$, where $\mathrm{s}$ is the standard deviation or measurement error, and $\mathrm{s}^{2}$ is the variance, as previously described elsewhere $[10,25,26]$.

\subsection{Statistical Analysis}

The amplitude of the LH pulse in response to GnRH was computed from the raw data as the difference $(\Delta)$ between the maximum height of the LH response and the LH plasma levels observed at the sampling interval immediately before the stimulation.

For the ISR, the maximal LH response to the GnRH bolus was computed as the difference between the highest LH concentration $(\Delta)$ after the GnRH bolus and the LH levels at time 0 of the test.

We tested data for statistically significant differences between the groups after analysis of variance (one-way ANOVA) by use of the Student's $t$-test for paired and unpaired data, as appropriate. Data are expressed as mean \pm SEM. 


\section{Results}

Hormonal parameters of the subjects under study are summarized in Table 1. After 90 days of treatment, both LH and FSH plasma levels significantly increased with no changes in any other hormonal parameters, including estradiol (Table 1). All patients responded positively to the treatment, since in all of them, the plasma levels of both gonadotropins increased significantly (Figure 1) but only 2 patients out of 17 reported the occurrence of menstrual bleeding close to the end of the treatment interval. As expected, FHA patients showed cortisol plasma levels close to the upper limits of normality according to our laboratory, in the range of 5-19 $\mu \mathrm{g} / \mathrm{dL}$ (Table 1).

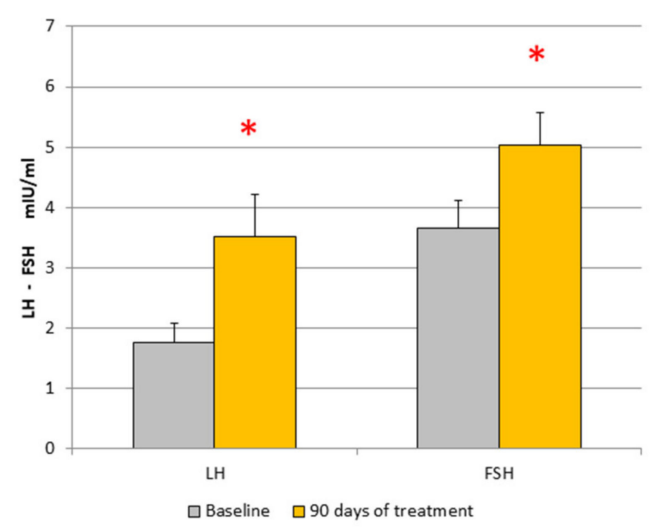

Figure 1. Plasma levels of LH and FSH before and after 90 days of treatment with $5 \mathrm{ng}$ of estradiol every day. Both gonadotropins were significantly increased by the treatment. ${ }^{*} p<0.05$ vs. baseline.

The GnRH bolus induced an LH response that had a greater amplitude after the treatment interval (Figure 2). An improved response was observed both in terms of the plasma concentration and also the ISR computation. It is notable that, as expected, the amplitude of the LH response obtained using ISR computations was of a lower entity than what was observed for the blood concentration (Table 2).

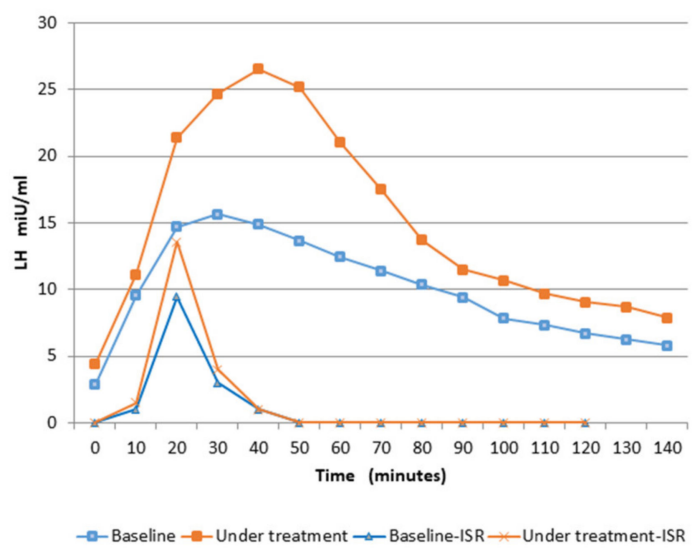

Figure 2. LH response profile (mean of 17 patients) to GnRH stimulation before (orange) and after treatment (blue). When Instantaneous Secretory Rates (ISR) were computed, a completely different LH response was disclosed. Both in terms of the plasma concentration and after ISR computation, the LH response to the GnRH bolus was greater than at baseline. The GnRH bolus was injected at time 0. 
Table 1. Hormonal parameters of patients with FHS at baseline and after hyper-low E2 administration.

\begin{tabular}{|c|c|c|c|c|c|c|c|c|c|}
\hline $\begin{array}{l}\text { Patient } \\
\text { sn }=17\end{array}$ & $\begin{array}{c}\mathrm{LH} \\
\mathrm{mUI} / \mathrm{mL}\end{array}$ & $\begin{array}{c}\text { FSH } \\
\mathrm{mUI} / \mathrm{mL}\end{array}$ & $\begin{array}{c}\text { PRL } \\
\mathrm{ng} / \mathrm{mL}\end{array}$ & $\begin{array}{c}\mathrm{E} 2 \\
\mathrm{pg} / \mathrm{mL}\end{array}$ & $\begin{array}{c}P \\
\mathrm{ng} / \mathrm{mL}\end{array}$ & $\begin{array}{c}\text { Cortisol } \\
\mu \mathrm{g} / 100 \mathrm{~mL}\end{array}$ & $\begin{array}{c}\mathrm{T} \\
\mathrm{ng} / \mathrm{mL}\end{array}$ & $\underset{\mathrm{ng} / \mathrm{mL}}{\mathrm{A}}$ & $\begin{array}{l}\text { Insulin } \\
\mu \mathrm{UI} / \mathrm{mL}\end{array}$ \\
\hline Baseline & $1.85 \pm 0.32$ & $3.44 \pm 0.43$ & $11.99 \pm 1.86$ & $33.46 \pm 8.05$ & $0.46 \pm 0.06$ & $15.9 \pm 3.5$ & $19 \pm 2.1$ & $190.8 \pm 10.4$ & $2.86 \pm 0.45$ \\
\hline $\begin{array}{c}\text { After } \\
\text { treatment }\end{array}$ & $3.52 \pm 0.7^{*}$ & $5.02 \pm 0.54^{*}$ & $10.8 \pm 1.9$ & $28.67 \pm 4.9$ & $0.85 \pm 0.34$ & $16.1 \pm 2.9$ & $28.3 \pm 13$ & $214 \pm 29.76$ & $3.78 \pm 0.7$ \\
\hline
\end{tabular}


Table 2. Amplituse of LH response to GnRH test before and after the treatment interval.

\begin{tabular}{ccc}
\hline $\begin{array}{c}\text { LH Pulse } \\
\text { After GnRH Test }\end{array}$ & $\begin{array}{c}\text { Amplitude } \\
\text { (Plasma Concentration) } \\
\text { mIU/mL }\end{array}$ & $\begin{array}{c}\text { Amplitude } \\
\text { (ISR) } \\
\text { mIU/mL }\end{array}$ \\
\hline Baseline & $15.2 \pm 1.6$ & $9.5 \pm 0.9 \$$ \\
\hline After 12 weeks of treatment & $24.6 \pm 5.7^{*}$ & $13.5 \pm 2.4 * \$$ \\
\hline \multicolumn{2}{c}{$*<0.05$ vs. baseline; $\$ p<0.05$ vs. plasma concentration. }
\end{tabular}

When the Naloxone test was evaluated, both LH and cortisol responses were considered. At baseline conditions, LH showed a response after 30 to $60 \mathrm{~min}$ after the bolus, while, after the treatment interval, the $\mathrm{LH}$ response to the naloxone bolus occurred at time $+15 \mathrm{~min}$ (Figure 3).

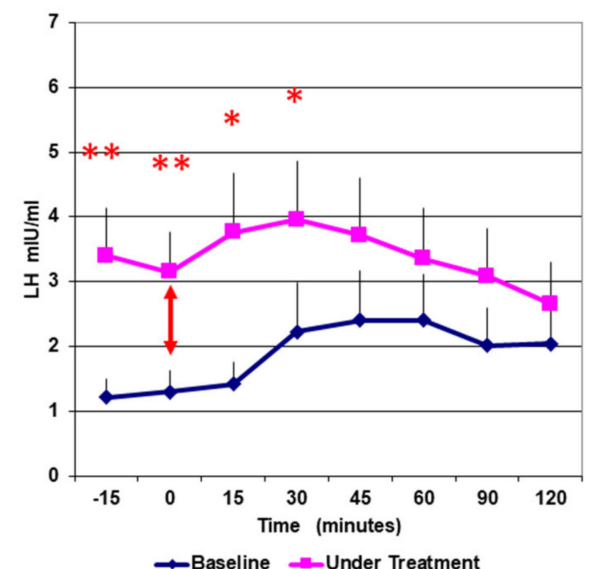

Figure 3. LH response after Naloxone infusion. LH showed a response after the treatment interval. The arrow indicates the time that the bolus was infused. ${ }^{*} p<0.05 ;{ }^{* *} p<0.01 \mathrm{vs}$. baseline.

When considering cortisol, significant modifications occurred after the treatment interval. In fact, while no response was observed for cortisol under baseline conditions, after the treatment interval, naloxone infusion was able to induce a significant change in the cortisol profile with respect to baseline conditions (Figure 4). In fact, cortisol plasma levels increased within $30 \mathrm{~min}$ from infusion of the naloxone bolus, resulting in a higher cortisol response than that observed under baseline conditions (Figure 4).

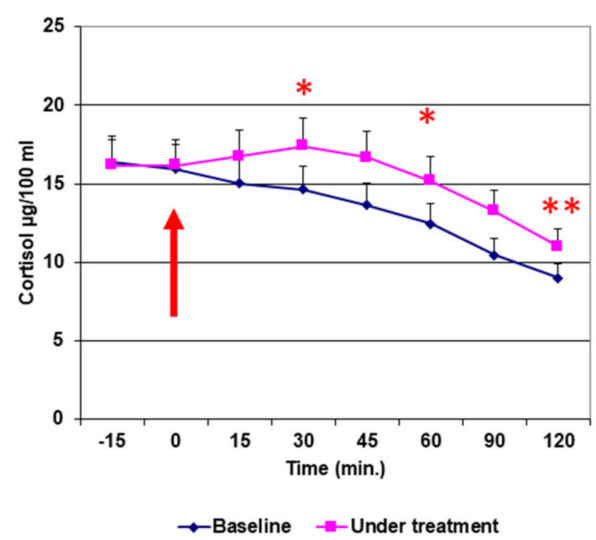

Figure 4. Cortisol response to naloxone infusion. After the treatment interval, cortisol again showed a response to the opioid-receptor antagonist. The arrow indicates the time that the bolus was infused. * $p<0.05,{ }^{* *} p<0.01$ vs. baseline. 


\section{Discussion}

The present study supports the idea that the administration of a very low amount of estradiol, as low as $2.5 \mathrm{ng} / \mathrm{mL}$, two times a day, is able to modulate neuroendocrine control of both LH and cortisol secretion in patients with FHA.

Recent reports demonstrated that the administration of a weak estrogen. i.e., estriol, was able to positively affect the neuroendocrine control of hypothalamus-pituitary function both short- [16] and long-term treatment intervals [17]. In fact, the use of weak estrogen resulted in reactivation of hypothalamic-pituitary control, probably inducing both greater expression/function of the receptor for GnRH as well as improving the synthesis/production of LH at the gonadotropic cell level [16,17], as also previously demonstrated in patients affected by Kallman Syndrome treated with estriol [27].

Our present data are in perfect agreement with previous studies $[16,17,27]$ and support the idea that positive effects are also induced by the administration of very low doses of estradiol. In fact, at baseline, the administration of very low doses of estradiol induced the same positive effects reported when administering estriol as a short- or long-term treatment [16,17]. It is well worth noting that in our study, no changes in estradiol plasma concentrations were observed during the treatment interval, thus confirming that the dose administered was really low and did not affect the mean plasma estradiol concentration.

When, after the treatment interval, patients underwent the GnRH stimulating test, a significant increase in the LH response was found, similar to what has been observed in patients affected by Kallman Syndrome [27] or FHA [16,17] following treatment with estriol, both in terms of the rough plasma concentration as well as ISR computation. This result is consistent with the specific reactivation of the gonadotropes' ability to respond to exogenous $\mathrm{GnRH}$ administration thanks to the positive effects of the low levels of estradiol administered on the gonadotropic cells.

The present data support the hypothesis that very low estradiol doses, similarly to estriol, are able to induce mechanisms that are at the basis of the positive feedback determined by estrogens, such as estriol, at the pituitary level. This is similar to what has been observed in Kallmann Syndrome [27], FHA [16,17], and non-human primates [28]. In addition, our data confirm the observation that, in non-GnRH-deficient patients, treatment with epimestrol induces increases in both basal and GnRH-induced LH release from gonadotropes [29]. These reports, together with the present study, indicate the positive role of very-low-dose estradiol administration in centrally reactivating mechanisms on the basis of the positive feedback, mainly at the hypothalamic-pituitary level. This positive role was recently found to be at the basis of the control of the reproductive axis through kisspeptin secreting neurons on which the positive or negative feedback of gonadal steroids (i.e., estradiol) acts [30].

As additional confirmation of the central effects of the very low estradiol dose we used, there are the effects made on the response to the naloxone test. In fact, it is well known that both LH and cortisol rarely respond to the administration of a naloxone bolus in FHA, since they are strongly affected by both opioid hypertone and the hypoestrogenic condition [31-33]. This kind of defective response is typical of other physiopathological conditions, such as Turner syndrome, and postmenopause [31]. The key role of estrogen modulation on the opioidergic control of gonadotropin secretion is demonstrated by the fact that naloxone infusion does not induce any LH response in prepubertal girls, while such response appears with the onset of puberty when estrogen priming starts to play a role centrally [31]. Our present data demonstrate that, though hypoestrogenic, our patients with FHA showed a minimal LH response to the naloxone bolus that was significantly modified and improved by the low dose of estradiol administered. Indeed, this LH response appeared to occur in an anticipatory manner with respect to what was observed at baseline conditions.

What we observed on the cortisol side is interesting. As previously reported [33], no cortisol response was observed in our FHA patients under naloxone infusion, similarly to what has been observed in postmenopausal women [31]. After 3 months of hyper-low estradiol administration, though no changes occurred in mean cortisol plasma levels, a specific change in the cortisol response to naloxone infusion was observed. In fact, cortisol showed a distinct rise, thus supporting the hypothesis 
that specific neuroendocrine modulation took place on the ACTH (Adreno Corticotropin Hormone) pathway thanks to the hyper-low estradiol dosage administered. In fact, this modulation seemed to restore the ability of the cortisol axis to respond to the opioid antagonist. The very low estradiol doses administered probably modulated/adapted the naloxone binding ability acting also on the opioidergic receptor expression/synthesis, thereby inducing/permitting the cortisol response to occur. Such observation supports the hypothesis that administration of a very low estradiol dose somehow modulates the inner factors of the equilibrium of the hypothalamus-pituitary-adrenal axis, leading it to be closer to a normal response. In fact, a previous report clearly demonstrated that FHA patients respond not only to naloxone [33] but also to a CRF (Corticotropin Releasing Factor) bolus in the presence of hypogonadotropic hypoestrogenism [34].

Such data fit perfectly with what was recently published by Lovallo et al. [35], who reported that under stressful conditions, depending on the severity of stressors, other neuroendocrine axes are impaired. Indeed, other than the CRF-ACTH-adrenal axis, a second neuroendocrine pathway based in the amygdala acting on the paraventricular nuclei and the lucus ceruleus loses its normal control on the norepinephrine neuronal network located in this area [35], impairing the functioning of specific CRF and arginine-vasopressin (AVP) neurons that act directly on ACTH release from the pituitary [36]. According to Lovallo et al. [35], in FHA, the ability of cortisol to respond to naloxone infusion depends on the severity of the stressors [35]. In fact, the cortisol response to naloxone chlorhydrate was observed only in low or mildly stressed patients but not in severely stressed patients with FHA. Based on the lack of any cortisol response to the naloxone test, our subjects belong to the latter group, and they recovered their cortisol response to naloxone infusion after administration of a hyper-low dose of estradiol.

According to this model [35], which is briefly schematized in Figure 5, our data let us infer that the very low dose of estradiol was probably able to positively modulate/affect the amygdala area, recovering the pathway impaired by severe stressors. This recovery might depend on estradiol-induced reactivation of the sensitivity to naloxone action and is perhaps related to greater expression of opioid receptors, thus permitting the occurrence of amygdala-driven stimulation on AVP [36] and probably CRF neurons, and, through them, on the ACTH release from the pituitary, thus inducing cortisol release from the adrenal glands. Obviously, it cannot be excluded that neuroendocrine mechanisms other than the ones depicted here might take place, thereby improving the pituitary function in FHA patients exposed to hyper-low dose estradiol administration.

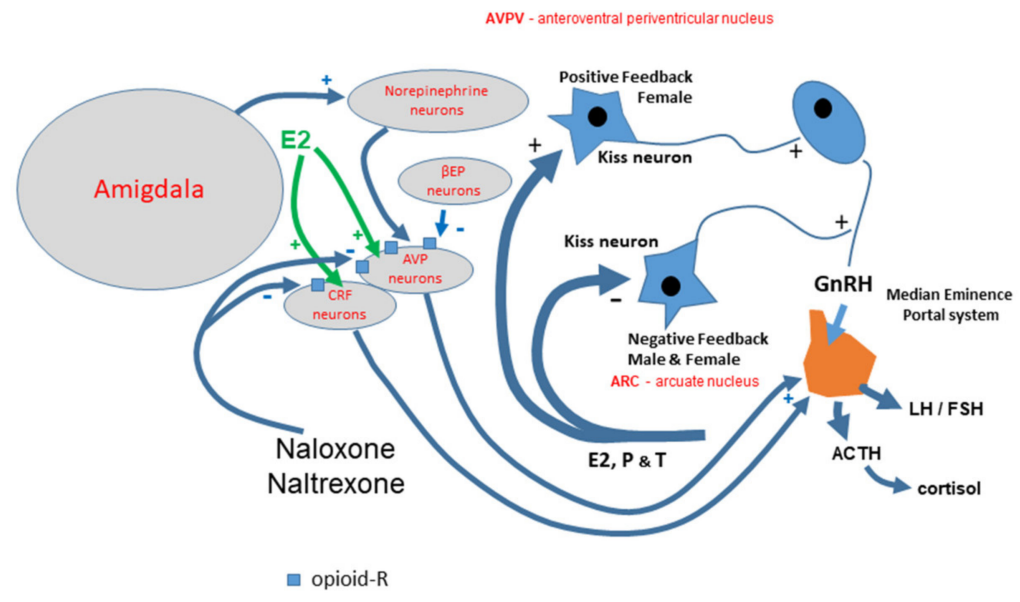

Figure 5. Putative mechanism that, according to current knowledge, might explain the recovery of the cortisol response to a naloxone bolus in Functional Hypothalamic Amenorrhea (FHA). Probably, a greater amount of opioid-R expression/synthesis was induced by the very low estradiol amount administered, while acting as positive feedback on kisspeptin-induced GnRH release. This permits a greater competitive effect of naloxone in binding to the receptors and displacing endogenous opioids such as $\beta$-endorphins ( $\beta E P$ ). The opioid-R blockade by naloxone allowed AVP (arginine vasopressin) and probably CRF neurons to be more active in stimulating ACTH-secreting cells at the pituitary level. 
In conclusion, our study, though limited by the small number of patients involved, demonstrates the positive role of estradiol administration at a dose as low as $5 \mathrm{ng} / \mathrm{mL}$ per day, on stress-impaired neuroendocrine function in FHA. It is worth noting that $2.5 \mathrm{ng} / \mathrm{mL}$ twice a day is a very low dose with respect to the amount of estradiol normally secreted in the blood. Normally, the estradiol level in the blood is up to $100-1000$ times less, being between $20-30 \mathrm{pg} / \mathrm{mL}$ and $250-350 \mathrm{pg} / \mathrm{mL}$ in the periovulatory phase. During menopause, hormone replacement therapy (HRT) reintroduces doses of estradiol as high as $1-2$ mg every day, combined with progestins, which blunts menopausal symptoms and reduces the concentration of gonadotropins through the restoration of negative feedback. In patients with FHA, neither contraception nor HRT are adequate for triggering the spontaneous restart of gonadotropin secretion, since they both trigger negative feedback. On the contrary, weak estrogens $[16,17]$ or a hyper-low estradiol dose seem to be more adequate to positively counteract the neuroendocrine mechanisms of stress that block the reproductive axis.

Though larger studies are needed to disclose whether short-term treatment of 10 or 15 days might be able to positively affect the reproductive axis, the present pilot study suggests that long-term daily administration of a hyper-low dose of estradiol acts positively on the impaired neuroendocrine status of patients with FHA.

Author Contributions: Conceptualization, methodology, software and formal analysis, A.D.G.; investigation, A.P., G.D., T.P., V.T., A.M.; data curation, G.D.; writing—original draft preparation, A.D.G.; writing-review and editing, A.D.G., T.S.; visualization, A.G.; supervision, A.D.G. All authors have read and agreed to the published version of the manuscript.

Funding: This research received no external funding.

Conflicts of Interest: The authors declare no conflict of interest.

\section{References}

1. Genazzani, A.D. Neuroendocrine aspects of amenorrhea related to stress. Pediatr. Endocrinol. Rev. 2005, 2, 661-668. [PubMed]

2. Meczekalski, B.; Podfigurna-Stopa, A.; Warenik-Szymankiewicz, A.; Genazzani, A.R. Functional hypothalamic amenorrhea: Current view on neuroendocrine aberrations. Gynecol. Endocrinol. 2008, 24, 4-11. [CrossRef]

3. Berga, S.L.; Mortola, S.F.; Girton, L.; Suh, B.; Laughlin, G.; Pham, P.; Yen, S.S.C. Neuroendocrine aberrations in women with functional hypothalamic amenorrhea. J. Clin. Endocrinol. Metab. 1989, 68, 301-308. [CrossRef]

4. Genazzani, A.D.; Petraglia, F.; Volpe, A.; Genazzani, A.R. Hypothalamic amenorrhea: Neuroendocrine mechanisms/stress-induced anomalies. Assist. Reprod. Technol. Androl. 1997, 9, 1-13.

5. Genazzani, A.D.; Despini, G.; Chierchia, E.; Benedetti, C.; Prati, A. Pharmacological and integrative treatment of stress-induced hypothalamic amenorrhea. In Frontiers in Gynecological Endocrinology; ISGE series; Genazzani, A.R., Tarlatzis, B., Eds.; Springer International Publishing: Cham, Switzerland, 2015; Volume 3, Chapter 9; pp. 69-84.

6. Yen, S.S.C. Effects of lifestyle and body composition on the ovary. Endocrinol. Metab. Clin. N. Am. 1998, 27, 915-926. [CrossRef]

7. Genazzani, A.D.; Gastaldi, M.; Volpe, A.; Petraglia, F.; Genazzani, A. Spontaneous episodic release of adenohypophyseal hormones in hypothalamic amenorrhea. Gynecol. Endocrinol. 1995, 9, 325-334. [CrossRef]

8. Meczekalski, B.; Podfigurna-Stopa, A.; Genazzani, A.R. Why kisspeptin is such important for reproduction? Gynecol. Endocrinol. 2011, 27, 8-13. [CrossRef]

9. De Nicolao, G.; Liberati, D.; Veldhuis, J.D.; Sartorio, A. LH and FSH secretory responses to GnRH in normal individuals: A nonparametric deconvolution approach. Eur. J. Endocrinol. 1999, 141, 245-256.

10. Genazzani, A.D.; Petraglia, F.; Benatti, R.; Montanini, V.; Algeri, I.; Volpe, A.; Genazzani, A.R. Luteinizing hormone $(\mathrm{LH})$ secretory burst duration is independent from $\mathrm{LH}$, prolactin, or gonadal steroid plasma levels in amenorrheic women. J. Clin. Endocrinol. Metab. 1991, 72, 1220-1225. [CrossRef]

11. Genazzani, A.D.; Petraglia, F.; Fabbri, G.; Monzani, A.; Montanini, V.; Genazzani, A.R. Evidence of luteinizing hormone secretion in hypothalamic amenorrhea associated with weight loss. Fertil. Steril. 1990, 54, 222-226. [CrossRef] 
12. Dobson, H.; Ghuman, S.; Prabhakar, S.; Smith, R. A conceptual model of the influence of stress on female reproduction. Reprod. Cambr. 2003, 125, 151-163.

13. Klein, D.A.; Paradise, S.L.; Reeder, R.M. Amenorrhea: A Systematic Approach to Diagnosis and Management. Am. Fam. Physician 2019, 100, 39-48.

14. Meczekalski, B.; Katulski, K.; Czyzyk, A.; Podfigurna-Stopa, A.; Maciejewska-Jeske, M. Functional hypothalamic amenorrhea and its influence on women's health. J. Endocrinol. Investig. 2014, 37, 1049-1056. [CrossRef]

15. Gibson, M.E.S.; Fleming, N.; Zuijdwijk, C.; Dumont, T. Where Have the Periods Gone? The Evaluation and Management of Functional Hypothalamic Amenorrhea. J. Clin. Res. Pediatr. Endocrinol. 2020, 12 (Suppl. 1), 18. [CrossRef]

16. Genazzani, A.D.; Podfigurna-Stopa, A.; Czyzyk, A.; Katulski, K.; Prati, A.; Despini, G.; Angioni, S.; Simoncini, T.; Meczekalski, B. Short-term estriol administration modulates hypothalamo-pituitary function in patients with functional hypothalamic amenorrhea (FHA). Gynecol. Endocrinol. 2016, 32, 253-257. [CrossRef]

17. Genazzani, A.D.; Meczekalski, B.; Podfigurna-Stopa, A.; Santagni, S.; Rattighieri, E.; Ricchieri, F.; Chierchia, E.; Simoncini, T. Estriol administration modulates luteinizing hormone secretion in women with functional hypothalamic amenorrhea. Fertil. Steril. 2012, 97, 483-488. [CrossRef]

18. American Psychiatric Association. Diagnostic and Statistical Manual of Mental Disorders, 4th ed.; American Psychiatric Association: Washington, DC, USA, 1995.

19. Genazzani, A.D.; Petraglia, F.; Pianazzi, F.; Volpogni, C.; Genazzani, A.R. The concomitant release of androstenedione with cortisol and luteinizing hormone pulsatile releases distinguishes adrenal from ovarian hyperandrogenism. Gynecol. Endocrinol. 1993, 7, 33-41. [CrossRef]

20. Oerter, K.E.; Guardabasso, V.; Rodbard, D. Detection and characterization of peaks and estimation of instantaneous secretory rate for episodic pulsatile hormone secretion. Comput. Biomed. Res. 1986, 19, 170-191. [CrossRef]

21. Genazzani, A.D. Application of peak-detection programs to clinical data. In Computers in Endocrinology: Recent Advances; Guardabasso, V., Rodbard, D., Forti, G., Eds.; Raven Press: New York, NY, USA, 1990; pp. 71-82.

22. Genazzani, A.D.; Rodbard, D. Evaluation of methods for detection of pulsatile hormone secretion: Sensitivity vs. specificity. Acta Endocrinol. (Cph.) 1991, 124, 295-306.

23. Genazzani, A.D.; Rodbard, D.; Forti, G.; Petraglia, F.; Baraghini, G.F.; Genazzani, A.R. Estimation of instantaneous secretory rate of luteinizing hormone in woman during the menstrual cycle and in man. Clin. Endocrinol. 1990, 32, 573-581. [CrossRef]

24. Veldhuis, J.D.; Fraioli, F.; Rogol, A.G.; Dufau, M.L. Metabolic clearance of biologically active luteinizing hormone in man. J. Clin. Investig. 1986, 77, 1122-1128. [CrossRef]

25. Gallinelli, A.; Matteo, M.L.; Volpe, A.; Facchinetti, F. Autonomic and neuroendocrine responses to stress in patients with functional hypothalamic secondary amenorrhea. Fertil. Steril. 2000, 73, 812-816. [CrossRef]

26. Facchinetti, F.; Fava, M.; Fioroni, L.; Genazzani, A.D.; Genazzani, A.R. Stressful life events and affective disorders inhibit pulsatile LH secretion in hypothalamic amenorrhea. Psychoneuroendocrinology 1993, 18, 397-404. [CrossRef]

27. Genazzani, A.D.; Santagni, S.; Chierchia, E.; Rattighieri, E.; Campedelli, A.; Prati, A.; Ricchieri, F.; Simoncini, T. Estimation of instantaneous rates and intrinsic characteristics of luteinizing hormone secretion in women with Kallmann syndrome before and after estriol administration. Reprod. Biol. 2011, 3, 284-293. [CrossRef]

28. Terasawa, E.; Kurian, J.R.; Guerriero, K.A.; Kenealy, B.P.; Hutz, E.D.; Keen, K.L. Recent discoveries on the control of gonadotrophin-releasing hormone neurones in nonhuman primates. J. Neuroendocrinol. 2010, 22, 630-638. [CrossRef]

29. Genazzani, A.R.; Facchinetti, F.; De Leo, V.; Picciolini, E.; Franchi, F.; Parrini, D.; Kicovic, P.M. Effect of epimestrol on gonadotropin and prolactin plasma levels and response to luteinizing hormone-releasing hormone/thyrotropin-releasing hormone in secondary amenorrhea and oligomenorrhea. Fertil. Steril. 1978, 30, 654-660. [CrossRef]

30. Oakley, A.E.; Clifton, D.K.; Steiner, R.A. Kisspeptin Signaling in the Brain. Endocr. Rev. 2009, 30, 713-743. [CrossRef]

31. Genazzani, A.R.; Petraglia, F. Opioid Control of Luteinizing Hormone Secretion in Humans. J. Steroid Biochem. 1989, 33, 751-755. [CrossRef] 
32. Genazzani, A.D.; Menozzi, R.; Del Rio, G.; Luisi, S.; Petraglia, F.; Genazzani, A.R. Acute infusion of naloxone, an opioid receptor antagonist, does not modify serum leptin concentrations in amenorrheic and healthy women. Fertil. Steril. 1998, 70, 924-926. [CrossRef]

33. Nappi, R.E.; Petraglia, F.; Genazzani, A.D.; D’Ambrogio, G.; Zara, C.; Genazzani, A.R. Hypothalamic amenorrhea: Evidence for a central derangement of hypothalamic-pituitary-adrenal cortex axis activity. Fertil. Steril. 1993, 59, 571-576. [CrossRef]

34. Meczekalski, B.; Tonetti, A.; Monteleone, P.; Bernardi, F.; Luisi, S.; Stomati, M.; Luisi, M.; Petraglia, F.; Genazzani, A.R. Hypothalamic amenorrhea with normal body weight: ACTH, allopregnanolone and cortisol responses to corticotropinreleasing hormone test. Eur. J. Endocrinol. 2000, 142, 280-285. [CrossRef]

35. Lovallo, W.R.; Acheson, A.; Vincent, A.S.; Sorocco, K.H.; Cohoon, A.J. Early life adversity diminishes the cortisol response to opioid blockade in women: Studies from the Family Health Patterns Project. PLoS ONE 2018, 13, e0205723. [CrossRef]

36. De Kloet, E.R. Hormones and the stressed brain. Ann. N. Y. Acad. Sci. 2004, 1018, 1-15. [CrossRef]

(C) 2020 by the authors. Licensee MDPI, Basel, Switzerland. This article is an open access article distributed under the terms and conditions of the Creative Commons Attribution (CC BY) license (http://creativecommons.org/licenses/by/4.0/). 